\title{
Breeding Approaches for Combating Climatic Irregularities - A Review
}

\author{
Prastuti Bhattacharyya* and M. Ramesh Kanna
}

Department of Plant Breeding and Genetics, Assam Agricultural University, Jorhat-13, India

*Corresponding author

Keywords

Climate change, Evolutionary phase, Participatory plant breeding, Sustainability

Article Info

Accepted:

26 April 2020

Available Online:

10 May 2020

\begin{abstract}
A B S T R A C T
Climate change is one of the most concerned subjects of discussion at present. The change may be slow but the fact that even a slight change of this could lead to great devastation, is not at all ignorable. The time to cease the alarming climate change has already been at its peak and now, the need of the hour is to cope with it. The agricultural sector has already seen phases of raising crop productivity but this had huge impacts on the environment. This time, there is a need of 'sustainability' to come into play. This is possible by increasing the base genetic variability and emphasizing on the Evolutionary Phase of plant breeding. This further requires the collaboration of classical or traditional breeding techniques with the modern biotechnological tools. Also, there had been a loss of germplasm i.e. the land races, with the adaptation of high yielding varieties. The idea of Participatory Plant Breeding (PPB) has helped in reconsidering the breeding lines that the farmers usually suggest and this has broken the chain of uniformity, thereby conserving the genetic variability within different areas as per the specificity and preferences of the farmers. Moreover, the employment of traditional knowledge in combination with the most advanced technologies shall help in attaining faster acclimatization to the newly developed lines. With the escalating population and growth in climatic irregularities, now expects plants with greater adaptability, productivity and sustainability. This article will help in reconsidering all the aspects of plant breeding that probably do not find much importance in today's developed and technological era but holds good position in attainment of sustainability and adaptability to the changing climate.
\end{abstract}

\section{Introduction}

The alarming climate change is becoming a global threat to life in the planet. However, this is not ignorable that it is due to the humans that the earth is facing such unprecedented alterations in the climatic patterns. As per the fifth assessment report of the UN intergovernmental panel on climate change (IPCC), the average global temperature has seemed to rise by $0.85^{\circ} \mathrm{C}$, from the year 1880 to 2012. Also, a rise of about $19 \mathrm{~cm}$ was observed in global average sea level from the year 1901 to 2010. Besides, alterations in the rainfall pattern, air motions, etc. have also been observed. All these have drastically affected agriculture.

Food and health being the prime needs for survival, they demand environment friendly agriculture, so that a balanced ecosystem and sustainability coexist. A matter of concern here is, a lot of technologies have been developed in agriculture, but a very few of 
them has actually come into practice. This commonly occurs due to ignorance of farmers' needs and preferences. For agricultural sustenance, few things are basic. They are as follows:

The conservation of biodiversity and reducing the losses of land races that are not under cultivation since decades. Evolutionary plant breeding is supposed to generate variability in the genepool.

Reconsideration of farmers' preferences locally or/and globally. Participatory Plant breeding is an approach that aims at achieving his objective.

Bringing the ideas of traditional knowledge into scientific developmental activities.

\section{Climatic irregularities and their affects on agriculture}

Climate change is believed to drastically affect agriculture, as agriculture is highly correlated to environment. Change in the environmental pattern will affect farming systems globally. Studying formal economic models, it has been estimated that, in the absence of effective counteraction, the overall costs and risks of climate change will be equivalent to a $5 \%$ decrease in global gross domestic product (GDP) each year (Stern 2005). If a wider range of risks and impacts is considered, the decrease in GDP could be as high as $20 \%$ or more, with a disproportionate burden and increased risk of famine on the poorest countries (Altieri and Koohafkan 2003). The most vulnerable people are the poor inhabitants of arid and semi-arid regions. Climate changes are predicted to have adverse impacts on food production, food quality (Atkinson et al., 2008), and food security. Also, this is going to affect people with 'disproportionate' malnutrition; 'disproportionate' because some will be over nourished, the others undernourished. Rise in global temperature would challenge crop yield and productivity, with least impact over pests and weeds.

The erratic rainfall pattern will drastically affect rice cultivation in the low lying rainfed areas. Similarly, crops affected by water logging, soil salinity, drought conditions are also going to face similar problems. Climate change is estimated to have adverse impacts on farming systems and cropping patterns.

\section{The genotype and environment relationship}

When a research is carried on, often the selection environment and the target environment varies. The selection includes the research stations while the target environment is mostly the farmers' field.

In the process of selecting a genotype, many genotypes are rejected which now may not seem to fit the environments presently, but may have abilities to cope with the (changing) environmental scenario in the near future. The genotype $\mathrm{x}$ environment interaction plays a major role in plant breeding. But when the $G$ $\mathrm{x} E$ interaction is significantly large, it is not possible to ignore them.

Then two strategies remain: (1) to avoid them by selecting genotype(s) that is broadly adapted to the entire range of target environments, or (2) to exploit them by selecting a range of genotypes, each adapted to a specific environment (Ceccarelli, 1989). The second strategy sounds more meaningful as each genotype that is selected is naturally adapted to that particular environment and is at its best performance. Whereas, when a genotype is allowed to cope with multiple or a wide range of (unfavourable) environments, it will only show considerable productivity. 
Agriculture and the environmental scenario

After the rediscovery of Mendel's work, changes occurred in plant breeding, which affected the evolution of plants, particularly of the domesticated species and of their evolutionary potential (Ceccarelli 2009b). First of all, plant breeding as shifted from the farmers' field to the research stations and experimental plots. What was previously the job of the farmers, was now controlled by a handful of scientists.

Secondly, now the primary objective was to introduce widely adapted crop species rather than locally adapted varieties. This change affected the natural ecosystems and the locally adapted varieties were not of least importance. Thirdly, plant breeding gradually went from publicly to privately funded and this changed the outlook towards several crops. Some food crops or so called "orphan" crops now lost importance and this directly affected the lives of several poor farmers who were dependent on these crops.

After the green revolution, widely adapted and high yielding crops were introduced. However, this adaptation referred to 'geographical' than 'environmental' and this was what was totally opposite to what farmers were doing since millennia. The increased use of irrigation water, fertilizers and pesticides not only harmed the poor farmers but also the environment and the latter cost us more.

\section{Agricultural biodiversity, traditional knowledge and climate change}

Biodiversity refers to the different life forms on earth. Regardless of size, each and every organism has a role to play in the ecosystem. But with the increasing uniformity among the cultivated plants and loss of species, has drastically affected the ecosystem.
Traditionally, farmers have been practicing mixed cropping, mostly in case of pulses, where many genotypes/ lines/ varieties were mixed together and sowed. The practice not only assured security against crop failure but also proved to significantly minimize pest attack, weeds and intra and inters crop competition. Besides, the land was divided into small plots and cultivation of different crops was practiced. However, with the commercialization of agriculture and introduction of high yielding varieties (HYVs) and other varieties, monoculture gained momentum. Small land holdings were amalgamated and a single variety/crop was grown. Monoculture has limited the crops' capacity to evolve in response to adverse environmental conditions, which has resulted in decrease in the yield stability of the cropping system. In contrast to it, varietal mixtures typically stabilize grain yield and minimize disease-induced yield losses as well as yield losses due to abiotic stresses (Finckh et al., 2000). This is due to the underlying diversity in those mixtures. Increased biodiversity has the potential to reduce the progress of crop epidemics, optimize yield stability, and enhance crop resilience in for combating climate change-induced stress.

\section{Evolutionary plant breeding}

One method of increasing genetic diversity within cereal crop populations is through evolutionary breeding (EB).

To gain back what is lost is not possible, but now there is a need to conserving what is left with us. Plant breeding has two main phases:

The evolutionary phase

The evaluation phase.

Scientists have mostly emphasized on the latter but understanding the importance of evolutionary phase is now of utmost urgency. 
Evolutionary phase is the basic phase in plant breeding and aims at the creation of genetic variation. It helps in enlargement of the genetic base or germplasm in order to increase the scope of further selection and facilitate the development of new varieties.

Evaluation phase is the second phase of plant breeding in which, genotypes are subjected to screening and then the superior ones are selected and evaluated, disregarding the rest. In this process of selection, a lot many genotypes are rejected which might result in limiting the germplasm diversity.

However, domestication of wild species, collection of germplasm, introduction of new species, protection of land races, can increase the genetic base. Variability can be created using conventional breeding methods such as crossing/hybridization, polyploidy breeding, mutation breeding and also by using biotechnological tools like recombinant DNA technology and somaclonal variation. Gene pyramiding can also bring desirable genes together and help create desirable variability.

Working on the evolutionary phase of plant breeding may be referred to as Evolutionary Plant Breeding.

Variability in a species help fight various aspects of climate change. If we suppose that, due to environmental suitability, a minor pest unpredictably, emerges to be major pest, then the loss is more if all the cultivated plants are of same type. Besides, the spread will be faster. Now, if we take account of a widely adaptable (geographically) variety which is cultivated globally and a situation arises where, unfortunately, an unfavourable environment occurs and the crop fails. It cannot be imagined how all of a sudden there will be a global crisis. This situation analysis gives us an overview that biodiversity is important for sustenance.

\section{Participatory plant breeding}

Participatory Plant Breeding (PPB) in particular, is referred as the kind of plant breeding in which farmers, as well as extension staff, seed producers, traders, NGOs, etc., participate in the development of a new variety. PPB is expected to produce varieties, which are targeted (focused on the right farmers), relevant (responding to real needs, concerns, and preferences) and appropriate (able to produce results that can be adopted) (Bellon, 2006). PPB aims at reconsidering farmers' needs and preferences. The bridge between the technologies developed and those have been actually adopted in the field, is large. PPB aims at developing varieties through technologies that will be accepted by the farmers' of the particular area. Besides, preferences based on gender differences are taken into account.

As other breeding methods, PPB too, starts with the generation of genetic variability which is completely the responsibility of the research institution. Then comes the selection of parents. But here, also lies the choices of the farmers in the selection procedure. Conventional crossing, as and when required is always done by the technical staff. There are various stages of selection and different on farm field trials are conducted in each farmer's field, independently, for the purpose. It is ensured that all genders equally participate in the process and help select a good variety for the region. The collaboration and the farmer-scientist interaction are advantageous because it increases the speed of adoption of a variety. Also, the genepool is not lost most frequently as there are constant changes in the pattern of selection as the choices tend to change over times. Using the same varieties in the same region, over a long period of time, often results in loss of local germplasm and may also decrease the productivity of the variety. 
In a nutshell, the advantages of PPB are as follows:

The time taken for adoption of a variety is reduced as farmers are also involved in the selection procedure.

PPB has helped farmers in developing skills and also in their empowerment.

The biodiversity is increased as different varieties have been selected in different areas within the same country, in response to different environmental constraints and users' preferences.

There have been objections to PPB, mainly pointing at the fact that plant breeding being the job of a breeding is supposed to be done by them. However, circumstantial evidence suggests that while plant breeding has been a success story in climatically, agronomically and economically favorable areas, and in the regions where the environment could be modified to create near-optimum growing conditions, it has been much less successful in less-favorable areas.

In the areas where it has been successful, plant breeding has posed environmental threats due to high usage of chemical inputs as required by modern varieties, and has drastically affected biodiversity. More recently, there is widespread concern about the use of the improperly called genetically modified organisms (GMOs) which, regardless of other considerations, represent yet another type of top-down technology. For these reasons, it may be useful to explore alternative avenues of plant breeding where the same science can be used in a different way. On the other hand, the quality of the varieties produced by PPB is questioned based on the uniformity and stability of the varietal characteristics as required for certification of a variety to be released. This can be overlooked by considering the fact that PPB although produces heterogeneous varieties, yet they suit a particular environment and heterogeneity in terms of genetic constitution has always proved to strengthen the germplasm diversity and adapt to unfavourable agronomic conditions.

The global climate change suggests climate resilient agriculture to come into play. The conservation of existing variability and emphasizing on the Evolutionary Breeding will definitely increase the genetic diversity, thereby establishing balanced and sustained ecosystems. Also, use of traditional knowledge and collaboration of the farmers with the researchers shall help in developing climate resilient varieties. The success rate may be slower in terms of yield but Participatory Plant Breeding aims for long term benefits and environment by contributing toward biodiversity conservation and is also a farmer friendly method.

\section{References}

Altieri, M. A., and Koohafkan, P. (2008). Enduring farms: climate change, smallholders and traditional farming communities (Vol. 6). Penang: Third World Network (TWN).

Atkinson, M. D., Kettlewell, P. S., Poulton, P. R., and Hollins, P. D. (2008). Grain quality in the Broadbalk wheat experiment and the winter North Atlantic oscillation. The Journal of Agricultural Science, 146(5), 541-549.

Bellon, M. R. (2006). Crop research to benefit poor farmers in marginal areas of the developing world: a review of technical challenges and tools. $C A B$ Reviews: Perspectives in Agriculture, Veterinary Science, Nutrition and Natural Resources, 1(70), 1-11.

Ceccarelli, S. (1989). Wide adaptation: how wide?. Euphytica, 40(3), 197-205. 
Ceccarelli, S. (2009). Evolution, plant breeding and biodiversity. Journal of Agriculture and Environment for International Development (JAEID), 103(1/2), 131-145.

Ceccarelli, S., Galie, A., and Grando, S. (2013). Participatory breeding for climate change-related traits. In Genomics and breeding for climateresilient crops (pp. 331-376). Springer, Berlin, Heidelberg.

Ceccarelli, S., Grando, S., Maatougui, M., Michael, M., Slash, M., Haghparast, R., and Labdi, M. (2010). Plant breeding and climate changes. The Journal of Agricultural Science, 148(6), 627-637.

Finckh, M., Gacek, E., Goyeau, H., Lannou, C., Merz, U., Mundt, C., and Wolfe, M. (2000). Cereal variety and species mixtures in practice, with emphasis on disease resistance.
Govindaraj, M., Vetriventhan, M., and Srinivasan, M. (2015). Importance of genetic diversity assessment in crop plants and its recent advances: an overview of its analytical perspectives. Genetics research international, 2015.

Murphy, K. M., Carter, A. H., and Jones, S. S. (2013). Evolutionary breeding and climate change. In Genomics and breeding for climate-resilient crops ( $\mathrm{pp}$. 377-389). Springer, Berlin, Heidelberg.

Song, Y., and Li, J. (2011). The role of biodiversity, traditional knowledge and Participatory Plant Breeding in climate change adaptation in karst mountain areas in SW China. Center for Chinese Agricultural Policy (CCAP).

Stern, N., and Stern, N. H. (2007). The economics of climate change: the Stern review. Cambridge University press.

\section{How to cite this article:}

Prastuti Bhattacharyya and Ramesh Kanna, M. 2020. Breeding Approaches for Combating Climatic Irregularities - A Review. Int.J.Curr.Microbiol.App.Sci. 9(05): 3118-3123. doi: https://doi.org/10.20546/ijcmas.2020.905.369 